\title{
ESTUDO TAXIONÔMICO DOS PSEPHENIDAE (COLEOPTERA: BYRRHOIDEA) DA AMAZÔNIA BRASILEIRA ${ }^{1}$
}

\author{
Maria Fernanda Souza FERNANDEZ ${ }^{2}$, Claudio Ruy Vasconcelos da \\ FONSECA $^{3}$, Paul J. SPANGLER ${ }^{4}$
}

RESUMO - Cinco espécies de Psephenidae, incluidas no gênero Pheneps, são assinaladas para a Amazônia brasileira, pela primeira vez: $P$. cursitatus Spangler; $P$. auariensis sp.nov.; $P$. leptophallus sp.nov.; P. roraimensis sp.nov. e $P$. simoides sp.nov.

Detalhes de peças anatômicas do adulto, da larva, estruturas da terminália masculina são apresentadas para todas as espécies e são fornecidos novos dados sobre registros geográficos.

Palavras-chave: Coleoptera, Psephenidae, Taxionomia, Pheneps, Amazónia

Taxonomic Study of Psephenidae (Coleoptera: Byrrhoidea) from Brazilian Amazon Basin

ABSTRACT - Five species of the family Psephenidae belonging to genus Pheneps are repported from the Brazilian Amazon Basin for first time, $P$, cursitatus Spangler; $P$. auariensis sp.nov,; $P$. leptophallus sp.nov.; $P$. roraimensis sp.nov. and $P$. simoides sp.nov. Illustrations for adults and larvae are provided and new geographic records are given.

Key-words: Coleoptera, Psephenidae, Taxonomy, Pheneps, Amazon Basin

\section{INTRODUÇÃo}

Os Psephenidae constituem um grupo de coleópteros aquáticos ainda pouco conhecidos na região Neotropical e poucos foram os estudiosos que se dedicaram aos aspectos taxonômicos. Explorando preferencialmente ambientes lóticos e limpidos, os imaturos são relativamente fáceis de serem encontrados, aderidos às partes submersas das rochas, sendo que os adultos, mais raros, podem ser capturados ou sobre as rochas ou sobre a vegetação adjacente aos rios e córregos (LeConte, 1861; GuérinMéneville, 1861; Horn, 1870; Kiesenwetter, 1874; Waterhouse, 1876; Grouvelle, 1898; Darlington, 1936; Hinton, 1937).

Atualmente ocorrem na região neotrópica, 7 gêneros, a saber: Ectopria Le Conte, 1853 para o Panamá; Dicranopselaphus Guérin-Méneville, 1861, descrito originalmente para o México; Eubrianax Kiesenwetter, 1874, para o Peru; Tychepsephus Waterhouse, 1876 para o Chile; Psephenops Grouvelle, 1898 para Grenada (St. Vincent); Pheneps Darlington, 1936 para Cuba, Colômbia, Haiti e

\footnotetext{
'Parte da Dissertação de Mestrado do 1" autor, apresentada ao Programa de Pós-Graduação do Instituto Nacional de Pesquisas da Amazônia - INPA / Universidade do Amazonas - UA, parte financiada pelo Programa de Eliminação da Oncocercose para as Américas - OEPA.

2Aluna do Curso de Entomologia do Programa de Pós-Graduação do INPA/UA, bolsista do CNPq Caixa Postal 478 69011-970 Manaus-AM.

${ }^{3}$ INPA - Coordenação de Pesquisas em Entomologia, C. P. 478, 69011-979 - Manaus - AM.

${ }^{4}$ Pesquisador do Smithsonian Institution, Natural History Museum, Dept. of Entomology, Washingnton D.C., USA.
} 
Suriname; Psephenus Horn, 1870 para o Peru, México e Brasil. Para o Brasil, até o presente, está assinalado somente o gênero Psephenus com as seguintes espécies: P. brasilianus Hinton, 1937; $P$. plaumanni Hinton, 1937 e $P$. darwini Waterhouse, 1880.

Particularmente para a Amazônia brasileira, nada havia sido realizado neste grupo, pelo menos nos últimos 50 anos e, como resultado de várias viagens realizadas às áreas indígenas na região amazônica durante os anos de 1995 e 1996, foi realizado um senso preliminar das espécies de Psephenidae, usando-se metodologia mista de coletas, tendo sido capturados adultos e imaturos. Os dados obtidos permitiram ter uma idéia preliminar sobre a distribuição geográfica e a diversidade, tendo sido assinalado pela primeira vez o gênero Pheneps com a espécie: P. cursitatus Spangler, 1987, juntamente com quatro espécies novas do mesmo gênero, aqui descritas.

\section{MATERIAL E MÉTODOS}

As armadilhas do tipo Pensilvânia com luz negra, foram instaladas a 0,50 $\mathrm{m}$ acima do igarapé. O local onde as armadilhas foram colocadas foi escolhido de forma aleatória, levando-se em conta o seguinte: presença de imaturos nas pedras e cascalhos; determinação da profundidade dos igarapés (30 a 50 $\mathrm{cm})$; presença de corredeiras; abundância de substratos para os imaturos; vegetação marginal, de modo a permitir que a armadilha pudesse ficar localizada sobre a água e eqüidistante de ambas as margens do igarapé. Estas foram acionadas no período compreendido entre $18: 00$ a 6:00 horas da manhã durante 2 a 5 dias seguidos.

Além da metodologia tradicionalmente utilizada, ou seja, luz negra, empregaram-se outros métodos de coletas. Para as armadilhas do tipo Malaise (confeccionadas em nylon branco e preto), também considerouse os mesmos parâmetros citados acima, sendo que as mesmas foram armadas perpendicularmente sobre 0 igarapé, a altura de $0,50 \mathrm{~m}$ da superfície da água.

A coleta com armadilha de lençol branco, com luz negra, processou-se sempre às margens dos igarapés, onde geralmente estão pousados os adultos; mas também coletou-se nas folhas dos arbustos e sobre as pedras, usando-se rede entomológica, bem como diretamente com as mãos.

Os espécimes imaturos foram diafanizados, fervendo-se em solução formada por 10 partes de água, uma parte de sabão líquido mais três pastilhas de Hidróxido de Potássio (KOH). Posteriormente, os exemplares foram mergulhados em ácido acético para neutralizar a ação da base, e montados provisoriamente em lâminas escavadas, sob lamínula, para observação ao microscópio estereoscópico kombistereo wild M3C com luz de halogênio.

Os adultos foram dissecados para estudo da genitália masculina. Os exemplares tiveram retirados os dois últimos tergitos abdominais, os quais eram submetidos a mesma solução 
acima descrita. Após a fervura por alguns minutos (o tempo de fervura depende da rigidez da peça, há necessidade de monitoramento constante para não amolecer demasiadamente) e, com auxilio de uma lupa, usando-se um alfinete especialmente preparado com a ponta em forma de micro-gancho, retiravase a genitália. Em seguida, a peça foi montada provisoriamente em lâmina escavada com gelatina para efetuar-se os esquemas anatômicos, sob lupa com câmara-clara. As escalas foram obtidas usando-se lâmina milimetrada sob a lupa e refletida através da câmara clara. Este mesmo procedimento foi empregado no caso dos esquemas para os imaturos.

A identificação do material coletado foi feita por comparação com os exemplares da coleção do Natural History Museum do Smithsonian Institution em Washington D.C. e confirmadas pelo Dr. Paul Spangler, especialista do referido Museu. Os espécimes estudados estão conservados em frascos de vidro contendo álcool etílico a $70 \%$, devidamente rotulados e depositados na coleção de invertebrados do Instituto Nacional de Pesquisas da Amazônia - INPA, Manaus, Brasil.

As informações sobre os dados de Geologia das áreas coletadas foram retiradas do mapa de Geologia do Brasil (1995); 2 Edição; Departamento Nacional da Produção Mineral.

\section{RESULTADOS}

Em um ano de coletas (abril-95 - abril-96) foram obtidos 32 adultos e 741 imaturos pertencente a subfamília Psepheninae, gênero Pheneps com 5 espécies, de acordo com a tabela 1 .

Estes dados mostram, ainda que preliminarmente, a distribuição geográfica que parece obedecer limites ecológicos ainda não muito claros, tais como temperatura da água, e o tipo de rocha. Embora tenham sido realizadas coletas em latitudes mais meridionais e próximas do equador $\left(2^{\circ} \mathrm{S}\right)$, não foi

Tabela 1. Número de espécies e indivíduos de adultos e imaturos de Psephenideos coletados áreas da Amazônia Brasileira .

\begin{tabular}{lccc}
\hline Local da coleta & Espécie & $\begin{array}{c}\text { N }^{2} \text { Indiv. } \\
\text { Adultos/lmaturos }\end{array}$ \\
\hline Posto Indigena de Maturacá (AM) Área Indígena Yanomami & cursitatus & 24 & 219 \\
Posto Indígena Auaris (RR) Área Indigena Yanomami & auariensis & 01 & 32 \\
Vila de Pacaraima (RR) Área Indigena Macuxi & simoides & 03 & 56 \\
Posto Indígena Xitei (RR) Área Indigena Yanomami & roraimensis & 01 & 434 \\
lgarapé do Tracoazinho (RO) Área Indígena Uruê-Hau-Hau & leptophallus & 03 & 00 \\
Totais & 05 & $\mathbf{3 2}$ & $\mathbf{7 4 1}$ \\
\hline
\end{tabular}


possivel coletar nenhum exemplar imaturo ou adulto de Psephenidae. Todavia, a literatura para o Brasil assinala distribuição, a partir da latitude $15^{\circ} \mathrm{S}$, em áreas mais altas que simulam, em alguns casos, climas subtropicais.

Ao efetuar-se a plotagem da distribuição geográfica dos exemplares coletados, verificou-se que, apesar de ter-se trabalhado mais em locais situados no Escudo das Guianas, foi possivel coletar em diferentes provincias geológicas (Tab. 2). De acordo com Fonseca \& Reyes-Castillo (1993) é provável que a diversidade geológica possa influenciar a distribuição dos táxons na Amazônia.

\section{Pheneps cursitatus Spangler, 1987}

Pheneps cursitatus Spangler, 1987: 219, Figs. 1 a 12, 15.

Esta espécie foi originalmente descrita de coletas realizadas em Cerro de La Neblina, Venezuela, não havendo qualquer outra citação na literatura sobre a sua distribuição geográfica. Deste modo, é o primeiro registro para o Brasil e para a Amazônia. Os exemplares coletados não apresentam variações morfológicas relevantes, e por conseqüência, não será necessária uma redescrição. No entanto, na descrição original não está incluída a da larva descrita a seguir:

\section{Descrição da larva de Pheneps} cursitatus Spangler, 1978 (Fig.1 a-m)

Corpo: Larva de último estádio (Fig.1h), formato achatado, oval, deprimida, apresenta a parte dorsal convexa e a ventral côncava. Cada segmento do corpo apresenta grandes expansões pleurais marginadas por franja compacta de cerdas bicolores; segmentos torácicos cobrindo completamente a cabeça e os apêndices locomotores em vista dorsal. Coloração geral aproximando-se do âmbar com manchas e pontos escuros distribuídos irregularmente. Sobre o dorso há uma leve linha dividindo longitudinalmente a larva. $\mathrm{Na}$ extremidade do oitavo tergito abdominal encontram-se protuberâncias de coloração mais escuras, onde estão localizados os espiráculos.

Cabeça: hipognata de coloração castanho-escura, profundamente pigmentada, mas pouco esclerotinizada. Sutura epicranial

Tabela 2. Formação geológica, localidade e ocorrência das espécies de Pheneps

\begin{tabular}{llllll}
\multicolumn{1}{c}{ ESPÉCIES } & P.cursitatus & P.roraimensis & P.auariensis & P.simoides & P.leptophallus \\
FORMAÇÃO & & & & \\
\hline $\begin{array}{l}\text { Guianense/P.I Maturacá } \\
\text { Guianense/PI.Xitei }\end{array}$ & $\times$ & $*$ & & \\
$\begin{array}{l}\text { Surucucú/PI.Auaris } \\
\text { Surumú/ Vila de Pacaraima }\end{array}$ & & & $\times$ & $\times$ \\
Pacaas Novas & & & & \\
\hline
\end{tabular}


(Fig. 1a) bastante evidente, tão longa quanto a cabeça, e em formato de "V"; quatro estemas bem desenvolvidos. Sutura Frontoclipeal distinta. Labro (Fig.1g) livre, transverso, com o ápice bilobado, apresentando uma saliência central pequena, convexa e conspicua; ângulos externos arredondados; cerdas curtas e fortes recobrindo a superficie do terço distal de ambos os lobos; os 3/4 proximais são glabros; um grupo de cerdas longas surgem nos cantos da borda anterior que é quase reta exceto pela saliência central. Epifaringe (Fig.1f) com o terço anterior possuindo densa cobertura de cerdas pequenas e fortes de coloração escura; terço médio e posterior com microcerdas irregularmente distribuídas em toda a superficie; borda antero-lateral com franja de cerdas longas. Antena 3-segmentadas (Fig.1a) sendo o $1^{\circ}$ segmento mais robusto e longo, aproximadamente o dobro do $2^{\mathrm{o}} ; 3^{\mathrm{o}}$ segmento muito curto, levemente mais longo e mais delgado que o cone sensorial, ambos inseridos no ápice do $2^{\circ}$ segmento; antenífero bem desenvolvido; $1^{\circ}$ segmento com cerdas pequenas e dispersas na região distal, e no ápice 3 cerdas longas, 4 vezes maiores que as demais. Presença de um par de cerdas longas próxima à base da antena. Maxilas (Figs.1b,c) apresentando gálea com uma franja de cerdas compostas cobrindo o terço médio da borda externa até o ápice, onde também são encontradas cerdas largas espatuladas surgindo do ápice da borda interna. Lacinia com cerdas robustas apicais, dentiformes, as duas extremas com ápices acuminados, e as duas centrais com ápice rombo; área apical da face dorsal com cerdas delgadas e pequenas. Palpo maxilar com quatro segmentos; $1^{\circ}$ segmento pequeno; $2^{\circ}$ segmento o dobro do comprimento do $1^{\circ}$, com uma cerda pequena e forte; $3^{\circ}$ segmento algo menor que o $2^{\circ}$ segmento com 2 cerdas apicais; $4^{\circ}$ segmento diminuto, mais estreito que os demais,apresentando ápice arredondado com 2 sensilas. Palpígero grande. Estipe alongado, sub-retangular; cardo alongado e desenvolvido. Lábio largo, com muitos cerdas longas na borda anterior e cerdas mais curtas na região mediana; Ligula totalmente coberta por cerdas fortes e curtas; mento com três pares de cerdas; palpos labiais 2segmentados, $1^{\circ}$ segmento coberto com cerdas longas e fortes; segmento apical curto e glabro; palpígero bem desenvolvido com cerdas posicionadas de modo a formar arcos, e um par de cerdas lateral semelhantes as do palpígero. Mandíbulas (Figs.1d,e) simples sem mola, com 2 dentes, um apical e outro subapical, sendo o apical proeminente e fortemente esclerotinizado, o subapical pouco conspícuo; prosteca alongada, bem desenvolvida com um tufo de cerdas alongadas, distintas das demais.

Tórax: Protórax bem desenvolvido, tão longo quanto o meso e metatórax reunidos. 

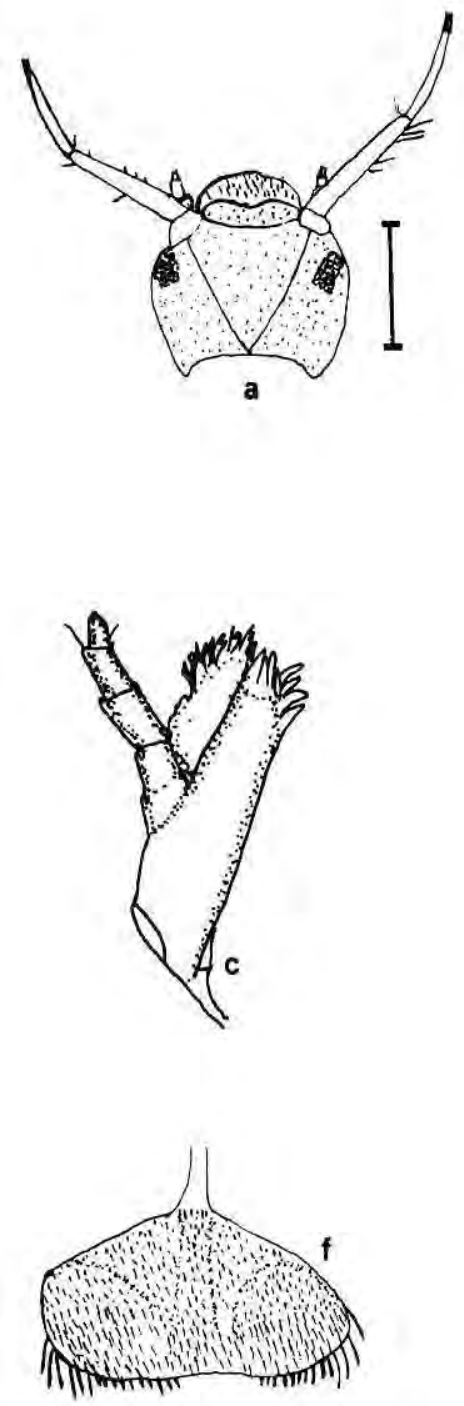
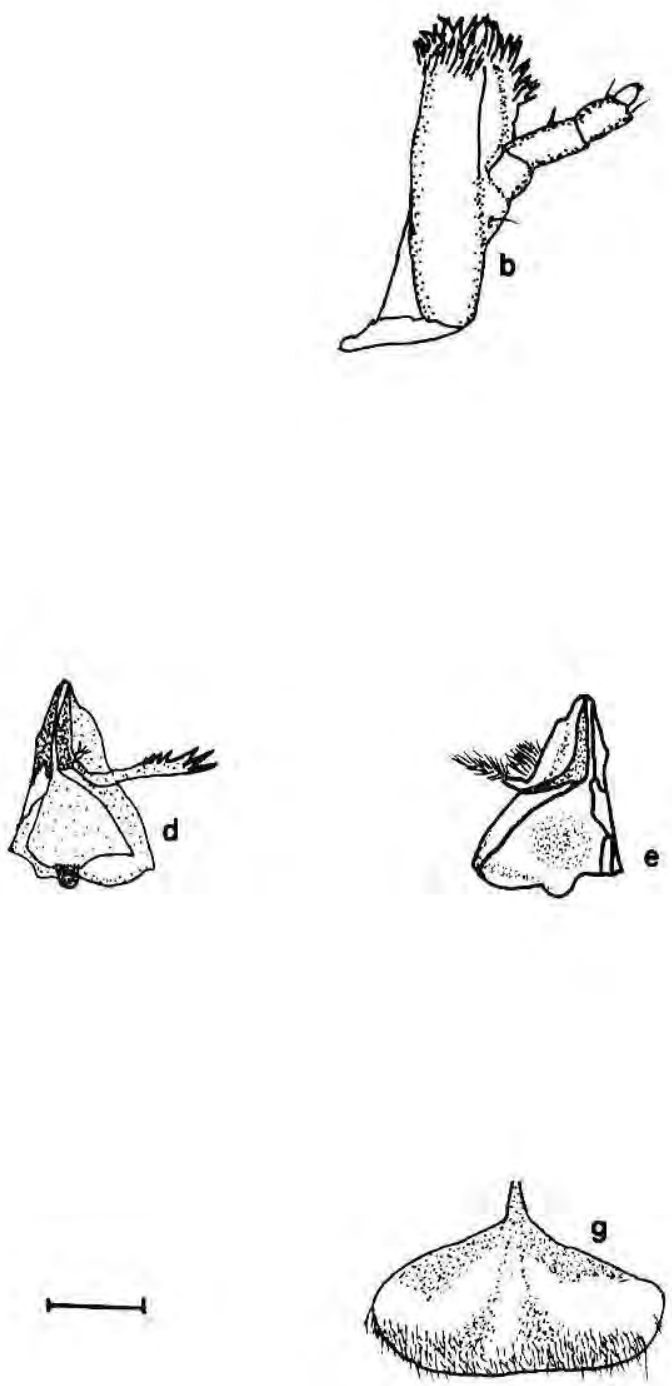

Figura 1. Pheneps cursitatus (larva). 1 a. Cabeça em vista dorsal; $1 \mathrm{~b}$. Maxila em vista dorsal; Ic. Maxila em vista ventral; 1d. Mandíbula em vista ventral; 1e. Mandíbula em vista dorsal; if Epifaringe; $1 \mathrm{~g}$. Labro. (Escalas: $1 \mathrm{a}=0,3 \mathrm{~mm} ; 1 \mathrm{~b}, 1 \mathrm{c}, 1 \mathrm{~d}, 1 \mathrm{e}, 1 \mathrm{f}, 1 \mathrm{~g}=0,1 \mathrm{~mm}$ ) 

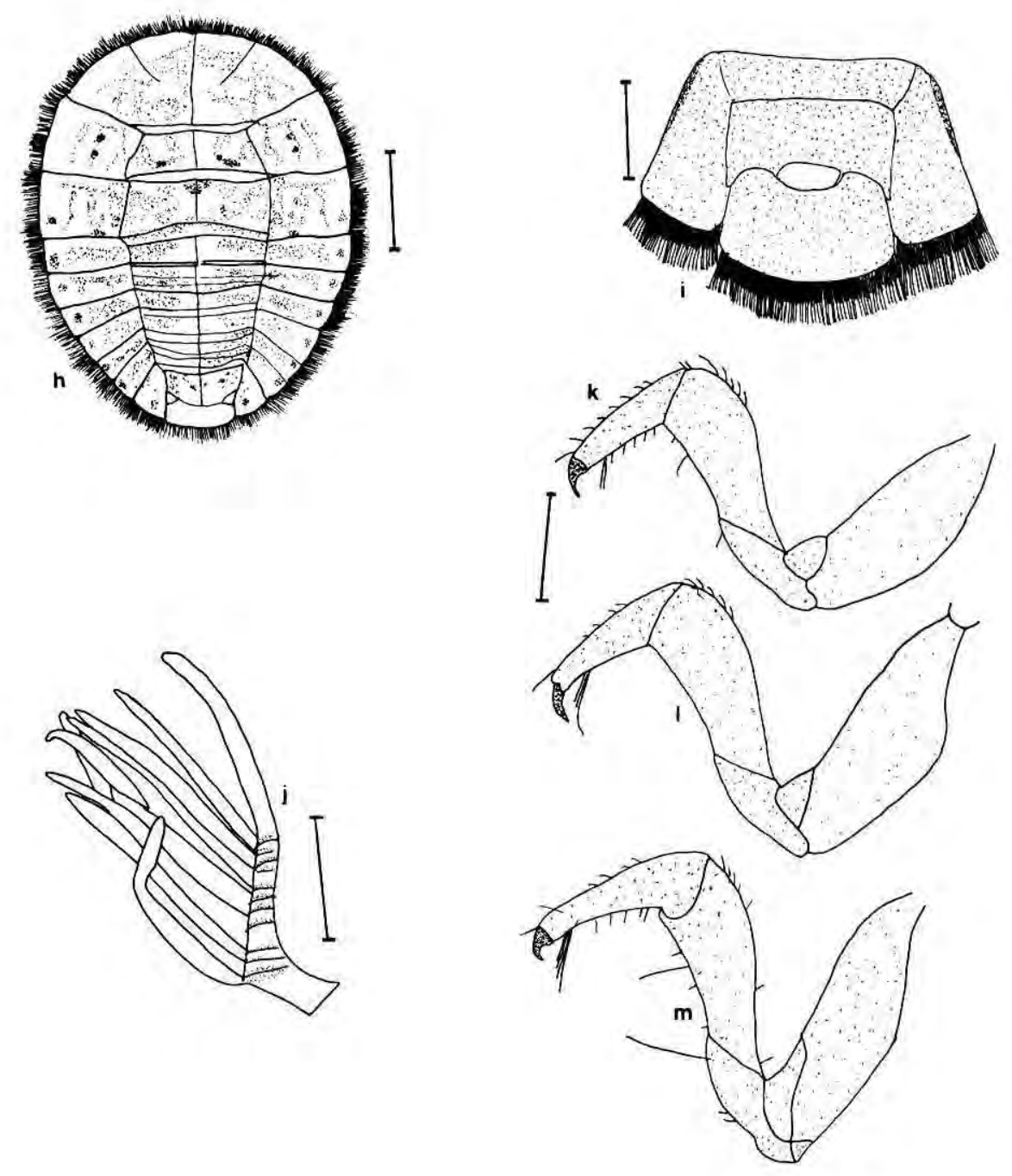

Figura 1-cont.. Pheneps cursitatus (larva). 1i. Esternitos No. 7,8,9 e 10; 1j. Brânquia; $1 \mathrm{k}$. Perna anterior; 11. Perna média; $1 \mathrm{~m}$. Perna posterior.(Escalas: $1 \mathrm{~h}=1 \mathrm{~mm} ; 1 \mathrm{i}=0,4 \mathrm{~mm} ; 1 \mathrm{j}=0,2 \mathrm{~mm}$; $1 \mathrm{k}, 11,1 \mathrm{~m}=0,3 \mathrm{~mm})$. 
Pernas (Figs.1k,1,m) levemente maiores das anteriores para as posteriores; coxas alongadas; Trocânter subtriangular, com algumas cerdas; Fêmur alongado, com cerdas dorso apicais e cerdas próximas à margem ventral; Tíbia alongada gradualmente afilada em direção ao ápice, com cerdas em ambas as margens, sendo que a margem ventral apresenta um tufo de cerdas longas próximo ao ápice; Tarsúngulo bem desenvolvido.

Abdome: com 9 segmentos visiveis dorsalmente; $8^{\circ}$ e $9^{\circ}$ segmentos retangulares, sem expansões laterais; $10^{\circ}$ segmento transverso reduzido, inserido entre $8^{\circ}$ e $9^{\circ}$ segmentos, e um grupo pequeno de asperites localizados lateralmente. Esternitos abdominais 3-6 com um par de brânquias ramificadas possuindo onze filamentos.

\section{Material}

examinado:

Adultos. BRASIL, Amazonas, Santa Izabel do Rio Negro, Posto Indígena de Maturacá, 31.iii. a 04.iv.1995, (19 machos e 02 fêmeas, armadilha luminosa; 2 machos e 01 fêmea, (armadilha Malaise) (Fernanda Fernandez; L.S. Aquino; V. Py-Daniel; M.J. Ferreira; W.L.S.Costa; U.C. Barbosa), INPA. Larvas. Idem, 30.iii.1995 (19 exemplares); 31.iii.1995 (171 exemplares); 05.iv. 1995

(29 exemplares) (Fernanda Fernandez), INPA.

Dados biológicos: Larvas associadas a adultos, coletadas manualmente na porção inferior das pedras submersas a pequena profundidade em riachos límpidos e lóticos. Adultos coletados com armadilha luminosa, colocada a $50 \mathrm{~cm}$ de altura da água.

\section{Pheneps auariensis sp.nov.} (Figs. 2 a-g )

\section{Descrição do adulto}

Comprimento total variando entre 3,2 a $3,5 \mathrm{~mm}$, corpo recoberto por cerdosidade fina, densa, pequena e recurvada (Fig. 2a), mais longa na parte anterior. Tegumento finamente pontuado. Coloração geral marrom escuro, palpos labiais, maxilares, clípeo, labro e os dois primeiros segmentos antenais mais claros.

Cabeça: Transversa. Borda frontal côncava e deprimida no ápice apresentando cerdas esparsas e delgadas; vértice convexo; antenas inseridas em protuberâncias (Fig. 2b), não ultrapassando o comprimento total do corpo; $1^{\circ}$ segmento grande, robusto, com ápice entumecido, medindo quase 3 vezes o comprimento do $2^{\circ}$. Segmentos 3-9 retangulares, delgados, decrescentes ligeiramente para o ápice; último segmento com ápice cônico. Olhos (Fig.2a) grandes, hemisféricos e proeminentes, situados medianamente na cabeça. Palpos maxilares grandes, 4-segmentados; $1^{\circ}$ segmento muito pequeno; $2^{\circ}$ segmento alongado, maior que os demais; $3^{\circ}$ segmento alongado, cerca de $1 / 3$ menor que o antecedente; $4^{\circ}$ segmento alongado, cilíndrico e algo menor que 


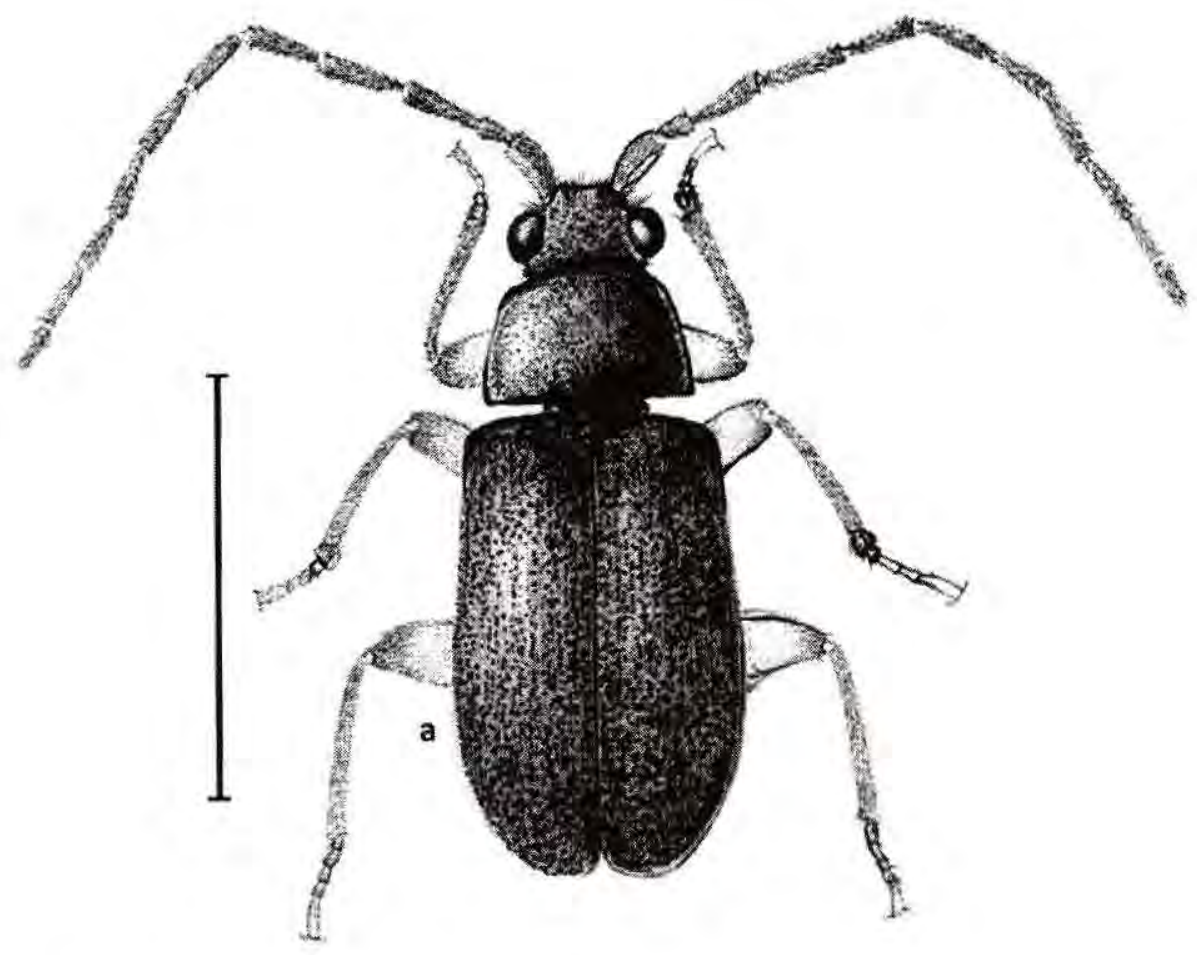

Figura 2. Pheneps auariensis. 2 a. Adulto em vista dorsal. (Escala $=2 \mathrm{~mm}$ )

o anterior, possuindo lateralmente em sua metade distal uma cânula mediano-longitudinal, terminando em um apêndice pequeno que ultrapassa o ápice propriamente dito do último segmento. Palpos labiais pequenos, 3 segmentados; $1^{\circ}$ segmento pequeno; $2^{\circ}$ segmento grande, robusto, maior que os outros, quase 3 vezes o tamanho do antecedente; $3^{\circ}$ segmento pequeno, com o ápice deprimido. Labro estreito, margem anterior arredondada. Clipeo ligeiramente convexo, com margem apical sub-reta, sutura clípeo-labial bem marcada.

Tórax: Pronoto transverso, levemente convexo, alongado na base; ângulos antero-laterais arredondados, postero-laterais retos. Escutelo mais largo que longo, raso, com as laterais convergentes formando um ângulo agudo no ápice. Élitros cerca de 3 vezes mais longos que o pronoto e cerca de $1 / 4$ mais largo do que a base do pronoto. Úmero arredondado. Cada élitro com 5 estrias indistintas, longitudinalmente. Prosterno moderadamente curto em frente as procoxas. Processo prosternal estreito, em forma de quilha, com o ápice invadindo o mesosterno que, por sua vez, é delgado entre as mesocoxas, com um sulco longitudinal estreito. Metasterno se prolongando por de trás das mesocoxas; com uma linha lon- 

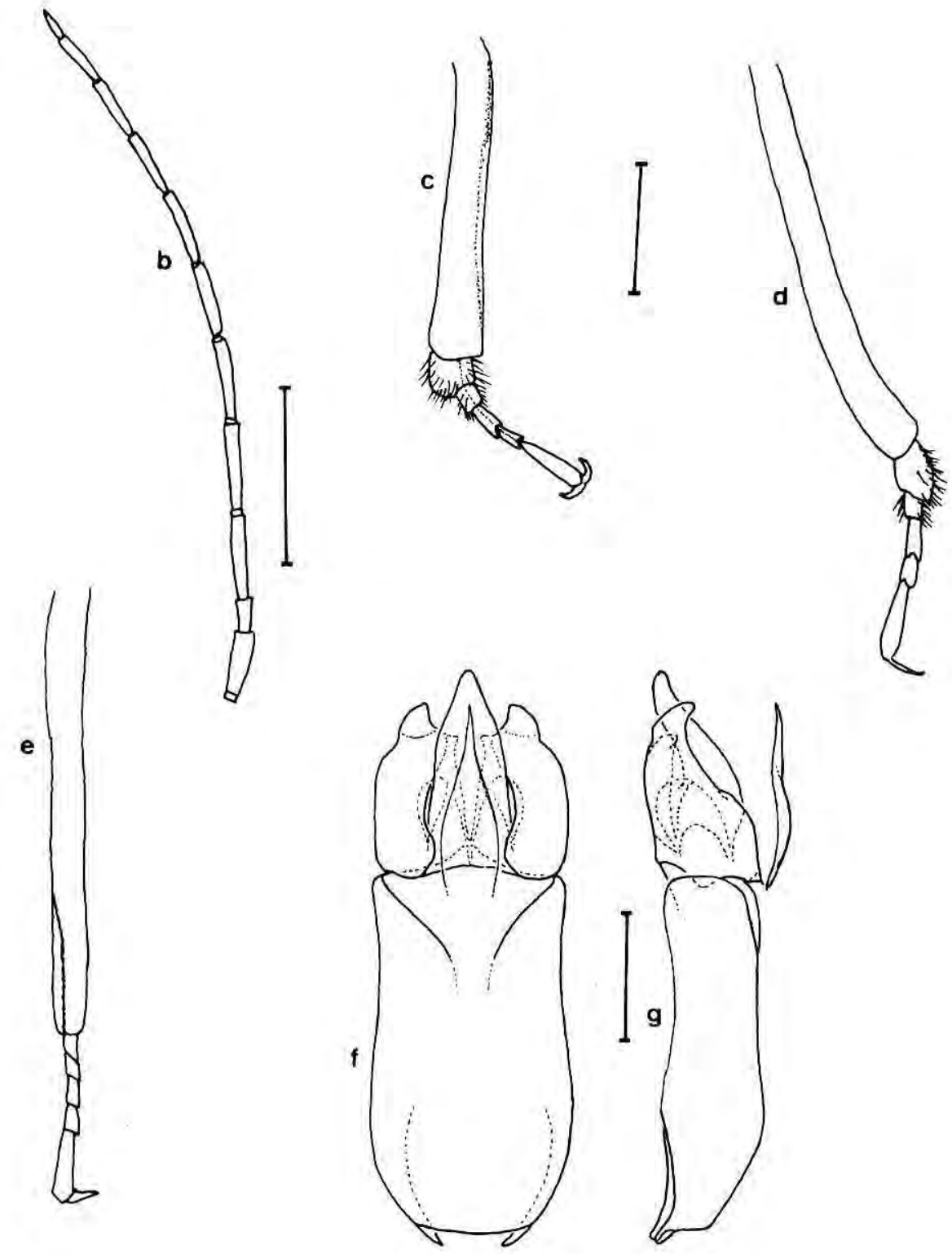

Figura 2 - cont.. Pheneps auariensis (adulto). 2b. Antena; $2 c$. Perna anterior; 2d. Perna média; 2e. Perna posterior; $2 \mathrm{f}$. Edeago em vista dorsal; $2 \mathrm{~g}$. Edeago em vista lateral. (Escalas: $2 \mathrm{~b}=$ $1 \mathrm{~mm} ; 2 \mathrm{c}, 2 \mathrm{~d}, 2 \mathrm{e}=0,3 \mathrm{~mm} ; 2 \mathrm{f}, 2 \mathrm{~g}=0,3 \mathrm{~mm})$ 